\title{
IGLESIA, INTERESES ECONÓMICOS Y TEOLOGÍA DE LA DOMINACIÓN. CONTRADICCIONES EN LA EVANGELIZACIÓN DE LA AMÉRICA ESPAÑOLA. PERÚ, SIGLO XVI*
}

\author{
CHURCH, ECONOMIC INTERESTS AND THEOLOGY OF DOMINATION. \\ CONTRADICTIONS IN EVANGELISM OF SPANISH AMERICA. \\ PERU, XVI CENTURY
}

\author{
Antonio Acosta**
}

\begin{abstract}
La presente investigación intenta mostrar, a partir de casos documentados, las contradicciones insalvables en que se movió la Iglesia católica durante la primera etapa de evangelización en el Perú colonial del siglo XVI. Por un lado, el choque entre los intereses que primaban en la dominación de las sociedades indígenas y la explotación de sus recursos económicos: fuerza de trabajo, productos, metales, etc., y, por otro, el objetivo de evangelizar a los nativos. Tal contradicción puede ser observada en específico en la labor del primer arzobispo de Lima Gerónimo de Loaysa, quien, más allá de su función pastoral dirigida a los indígenas, se dedicó a administrar una encomienda extrayendo altas cuotas de trabajo para realizar fructíferos negocios personales. Lo que revela este hecho particular es que los intereses económicos de los eclesiásticos se cruzaban de forma determinante con el ejercicio de su labor pastoral, limitándola seriamente en cuanto a la cobertura del clero y en cuanto a la relación con los feligreses, afectando también la transmisión de la doctrina a los indígenas.
\end{abstract}

Palabras claves: Evangelización, encomienda, Iglesia, Gerónimo de Loaysa, indígenas.

The current research attempts to show, based on documented cases, the insurmountable contradictions that shook the Catholic Church during the first stage of evangelization of the colonial Peru during the sixteenth century. On one hand, the clash between the interests that prevailed in dominating indigenous societies and exploiting its economic resources: workforce, products, metals, etc. and secondly, the objective of evangelizing the natives. This contradiction can be observed in particular in the work of the first Archbishop of Lima Geronimo de Loaysa, who, beyond his pastoral function aimed at indigenous, began to manage an errand extracting higher work quotas for fruitful personal business. Revealing this particular fact is that the economic interests of the church crossed decisively with the exercise of his pastoral work, seriously limiting in terms of coverage of the clergy and the relationship with parishioners, also affecting the transmission of the doctrine to the Indians.

Key Words: Evangelization, Errand, Church, Gerónimo de Loaysa, Natives.

\section{Introducción}

La colonización castellana de América, al igual que otras colonizaciones, tuvo desde sus orígenes como principal motor los intereses económicos ${ }^{1}$. Desde la financiación de los primeros barcos de Colón, el afán de ganancia permeó, de forma predominante, la mayoría de quienes pasaron al Nuevo Mundo, tanto a título individual como institucional ${ }^{2}$. El objetivo de la implantación del cristianismo entre los indígenas, por parte de la Corona castellana y del Papa, no escapó a los intereses económicos coloniales y estas páginas tratan de algunos casos que muestran las contradicciones insalvables en que se movió la Iglesia en este sentido: por un lado el choque entre los intereses que primaban en la dominación de las sociedades indígenas y la explotación de sus recursos económicos: fuerza de trabajo, productos, metales, etc., y, por otro, el objetivo de evangelizar a los nativos. Como consecuencia de ello, entre otros factores, la evangelización indígena adoleció de cierta inconsistencia y falta de suficiente atención por las autoridades españolas, en contra de lo que oficialmente se pretendía.

Es necesario hacer algunas puntualizaciones antes de abordar una propuesta como esta. La primera es que desde hace años se conoce bien que la relación entre españoles e indígenas, por no

\footnotetext{
* La base de la información de este trabajo corresponde a investigaciones que se pueden consultar en Acosta (2014).

** Universidad de Sevilla-IEAL. Sevilla, España. Correo electrónico: aacosta@us.es
} 
mencionar a mestizos, negros y otros grupos, fue compleja y que, sin perder su origen de conquista y de violencia, incluyó mecanismos de reacción, de resistencia y de utilización de recursos de la propia sociedad colonial por parte de los indios en su defensa ${ }^{3}$.

Por otra parte, igualmente es conocido que el proceso de evangelización, lejos de ser homogéneo, también fue complejo y diverso. En la medida en que la evangelización implicaba la existencia de dos referentes -el evangelizador y el que iba a ser evangelizado- $y$, también, en la medida en que tanto los componentes del elemento evangelizador como las sociedades indígenas fueron muy diferentes entre sí y diversos en el interior de cada uno de ellos, los rasgos que fue adquiriendo el proceso de evangelización variaron mucho en tiempo y lugar. Solo a título de ejemplos, en el mundo indígena los taínos del Caribe, y los lupaqa del altiplano andino tenían bases económicas y sociales profundamente diferentes ${ }^{4}$. Pero, por otro lado, en el campo de la Iglesia también tuvieron comportamientos distintos los franciscanos en Nueva España, los dominicos en Perú y muchos clérigos seculares en estos mismos lugares y en otros. Incluso, miembros de una misma orden y contemporáneos, como lo eran fray Bartolomé de las Casas y fray Jerónimo de Loaysa -primer obispo de Lima y de quien se hablará más adelante-, dominicos ambos, tuvieron posiciones muy diferentes respecto de la población indígena y de la evangelización.

En relación con esta observación es importante destacar que, aunque este trabajo pone énfasis en aspectos económicos de la evangelización, es claro que estos no eran la única dimensión de la relación entre la Iglesia y los indios. La implantación de la doctrina cristiana se encontraba inextricablemente conectada a problemas lingüísticos, a problemas vinculados a concepciones religiosas, al mundo político, a los procesos demográficos, a las diversas fórmulas arbitradas por los colonizadores para disponer de fuerza de trabajo, a las transformaciones que se fueron operando en el interior de las comunidades étnicas, etc., que también afectaron a la evangelización.

Por último, otra perspectiva que no se puede dejar de considerar, que se cruzaba con y afectaba a las anteriores, era la de los acontecimientos en España, en el resto de Europa y, especialmente, en Roma. Las decisiones tomadas fuera de América influyeron a veces de forma decisiva en la colonización, de tal manera que, para comprender cabalmente cuanto ocurría en el continente americano, es preciso combinar dos miradas, una hacia dentro y otra hacia fuera del mismo, articulándolas en una sola visión. En todo caso y a pesar de todos estos matices, a largo plazo las contradicciones que aquí se estudiarán se mantuvieron e influyeron poderosamente en generar un cristianismo como el que ha vivido gran parte de América Latina hasta el siglo XX. El caso elegido para mostrar algunos de los rasgos que pueden considerarse centrales en el origen colonial de este proceso es el de la archidiócesis de Lima en el virreinato del Perú. Aunque con lógicas singularidades, muchos de estos rasgos se ven confirmados en otras regiones de las Indias ${ }^{5}$.

\section{El plano episcopal}

Al comienzo de la conquista de los Andes, al igual que en otros territorios americanos, hubo frailes y clérigos actuando conjuntamente con las huestes de los conquistadores. La mayoría de ellos ha quedado anónima en la historia, pero algunos sobresalieron pronto en la vida colonial ${ }^{6}$. Este fue el caso de fray Vicente Valverde, o.p. quien participó junto a Francisco Pizarro en el proceso de la conquista de los Andes. Gracias a los vínculos de Pizarro en la corte, Valverde fue rápidamente nombrado primer obispo de Cuzco, la capital del Tahuantinsuyo y centro urbano estratégico en los Andes y, al igual que otros jerarcas de la Iglesia en la Colonia, además de ocuparse de sus obligaciones pastorales, tomó posiciones en la organización de la dominación colonial llegando a adquirir bienes en el botín de la conquista, entre ellos una encomienda de indios ${ }^{7}$.

Pero cuando los intereses mercantiles de los conquistadores les llevaron a fundar Lima, la nueva ciudad terminó convirtiéndose en la capital política de la gobernación del Perú, que todavía no era virreinato. Por su recién adquirida importancia política, en 1541 se creó una diócesis con sede en la ciudad y para cubrirla fue nombrado como primer titular fray Jerónimo de Loaysa, que era sobrino del poderoso fray García de Loaysa quien llegó a ser, en distintos momentos, confesor de Carlos V, presidente del Consejo de Indias, arzobispo de Sevilla y general de los dominicos ${ }^{8}$.

No obstante, en términos económicos y pese a su carácter portuario, Lima no tenía todavía la importancia de Cuzco como generadora de riqueza 
agraria, debido a la menor densidad de población indígena que había en sus alrededores en comparación con la sierra ${ }^{9}$. Reflejo de esta realidad era la diferencia existente entre el nivel de los diezmos de las diócesis de ambas ciudades. Mientras que en Lima los diezmos suponían solo 3.050 pesos en 1542 y ascendieron a casi 11.000 en 1548 , los de Cuzco importaban más de 55.000 pesos en este último año ${ }^{10}$. Fray Jerónimo de Loaysa llevaba mal esta diferencia y una de las manifestaciones de su descontento fue el conflicto que mantuvo con el segundo obispo del Cuzco, fray Juan de Solano. Este era también dominico como Loaysa y había llegado al Perú en 1544 acompañando al primer virrey del Perú, Blasco Núñez de Vela. Ya en 1545 Loaysa y Solano tenían diferencias por razones entre las que se encontraban los límites entre ambos obispados y el problema de los diezmos, asociado con lo anterior ${ }^{11}$.

Pero, además, Loaysa desarrolló una importante actividad para reforzar su posición tanto económica como política. Tras el asesinato de Francisco Pizarro en 1541, el nuevo gobernador del Perú, Cristóbal Vaca de Castro, con quien J. de Loaysa había viajado a Lima, le concedió una encomienda de indios. Vaca de Castro y el nuevo obispo de Lima eran ambos protegidos en Castilla por fray García de Loaysa y por Francisco de los Cobos, el poderoso secretario del emperador, de manera que no era extraño que se apoyaran políticamente entre sí. La encomienda de Loaysa era la de los indios de "Goancayo" (Huancayo), del cacique Chuquinparço ${ }^{12}$. Conviene recordar que esto sucedía precisamente en momentos en que Bartolomé de las Casas, dominico como Loaysa, se hallaba combatiendo en la corte a los encomenderos como a una auténtica plaga para los indios y para la propia soberanía real en Indias ${ }^{13}$.

Los enfrentamientos entre españoles en Perú se agravaron cuando el emperador decretó en 1542 las conocidas como Leyes Nuevas que, entre otras medidas, establecieron algo decisivo: que los todopoderosos encomenderos verían recortado drásticamente su poder al impedírseles que pudieran disponer con total libertad de la mano de obra de los indios de sus encomiendas. A partir de la puesta en práctica de las Leyes Nuevas el tributo o excedente económico que los encomenderos -como Loaysaextraían de sus indios, sería tasado y fijado en un documento, de forma que se pondría un límite al poder económico y político casi absoluto de que hasta entonces habían disfrutado. Otra decisión de las mismas Leyes era que los eclesiásticos no podrían ser titulares de encomiendas, ni a título personal ni como instituciones, como sucedía por ejemplo con conventos de órdenes religiosas y, por supuesto, personas como fray Jerónimo de Loaysa.

Lógicamente el obispo no vio con simpatía las Leyes Nuevas y no mantuvo una relación fácil con el virrey Blasco Núñez de Vela quien fue enviado desde Castilla para aplicar la nueva legislación en Perú. En el proceso de las conocidas como "guerras civiles", la reacción de los colonos vinculados a intereses encomenderos fue tan violenta que parece que llegaron a tratar la posibilidad de envenenar al virrey, precisamente en casa del propio obispo Loaysa ${ }^{14}$. Además, él mismo -que probablemente todavía mantenía su encomienda- mantuvo buenas relaciones con Gonzalo Pizarro, cabecilla de la rebelión de los encomenderos contra las Leyes Nuevas, hasta el extremo de que, cuando el virrey fue derrotado y degollado en Quito, el obispo se embarcó hacia España en 1546 con dineros de Gonzalo Pizarro para tratar de negociar la no aplicación de las Leyes Nuevas en Perú ${ }^{15}$. Es decir, que, aunque mantuvo las formas, el posicionamiento económico y político del obispo de Lima a favor de los intereses encomenderos fue claro en esta situación. En este agitado ambiente Loaysa redactó la primera Instrucción de la orden que se ha de tener en la Doctrina de los Indios, que se comentará más adelante ${ }^{16}$.

Pero el asunto no acabó aquí. La rebelión contra y la muerte del primer virrey del Perú movió al emperador a enviar a los Andes a alguien para restablecer el poder real, el sacerdote Pedro de la Gasca. Se dio la circunstancia de que Loaysa y La Gasca se cruzaron en Panamá y, tras conversar, el obispo de Lima decidió cambiar de opinión y regresar con el enviado del rey apoyándolo en su tarea de derrotar al rebelde Gonzalo Pizarro. Es decir, Loaysa desistió del encargo que le había hecho G. Pizarro y lo traicionó. Al llegar a Perú, La Gasca consiguió vencer a G. Pizarro y sus huestes, y después de la victoria se dispuso a hacer un nuevo reparto de encomiendas, siguiendo las directivas trazadas en las Leyes Nuevas y asistido siempre por el obispo de Lima, que se convirtió en un estrecho colaborador del nuevo gobernante La Gasca ${ }^{17}$.

Esta colaboración tuvo su recompensa y La Gasca otorgó al arzobispo una nueva encomienda de indios en el reparto que realizó con su ayuda, contraviniendo lo establecido en las Leyes Nuevas 
sobre eclesiásticos y encomiendas ${ }^{18}$. La encomienda que La Gasca concedió a J. de Loaysa estaba compuesta por indios Yauyos y otros de Lurigancho, en el distrito de Lima ${ }^{19}$. Estos indios los había heredado una María Escobar de sus dos anteriores maridos, los conquistadores Martín de Estete y Francisco de Chaves, y ahora estaba casada con Pedro Portocarrero quien, a su vez, también era encomendero no lejos de Cuzco. Portocarrero mantuvo contactos con $\mathrm{La}$ Gasca y Loaysa mientras estos decidían el nuevo reparto de encomiendas, pero se vio sorprendido cuando supo que los indios de su mujer habían sido concedidos al arzobispo y, en julio de 1549, decidió iniciar un pleito contra Jerónimo de Loaysa en la Audiencia de Lima. Ante la justicia, Portocarrero protestó e hizo ver la ventaja que respecto de él había conseguido Loaysa, cuya encomienda valoraba en 12.000 pesos anuales. No se puede comprobar si la estimación de Portocarrero era correcta, pero lo cierto es que la tasa anual de tributos -3.000 pesos en plata y oro, 300 ovejas, 50 indios de mita, 300 fanegas de trigo y otras tantas de maíz, más de 200 piezas de ropa, etc.- que los indios de Loaysa debían entregarle era muy importante. En todo caso, lo más relevante era el hecho de que Loaysa se había comportado como juez y parte en este reparto de encomiendas y que se había aprovechado de su posición política, próxima al presidente La Gasca, para obtener a título personal importantes y polémicos beneficios materiales.

En contra de la opinión de Portocarrero el pleito fue trasladado al Consejo de Indias en octubre de 1551 , posiblemente porque Loaysa creyera que sus intereses serían mejor defendidos en España que en Lima. En 1553, Loaysa no había comparecido en los trámites del proceso y no se puede precisar si mantuvo su encomienda y hasta cuándo, pero la realidad es que el arzobispo había recibido de $\mathrm{La}$ Gasca una segunda encomienda de manera ilegal, porque contravenía lo establecido por las Leyes Nuevas, y que la había defendido en términos jurídicamente agresivos.

El arzobispo probablemente tenía sus dos principales rentas en la cuarta episcopal del total del diezmo de su diócesis (el $25 \%$ anual) y en el valor del tributo de las dos encomiendas que había obtenido, la primera de Vaca de Castro y la segunda de La Gasca. Como mínimo con estas rentas Loaysa se introdujo pronto en el mundo de los negocios. Solo a título de ejemplo, a fines de la década de 1540 el arzobispo era propietario de varias casas en Lima cuando la propiedad inmobiliaria, según él mismo, proporcionaba una de las rentas más seguras de que podía disponerse ${ }^{20}$; en 1551 adquirió en 1.150 pesos un navío de un tal Juan Gaitán, vecino de México, que hacía el comercio con el virreinato del Perú desde Huatulco ${ }^{21}$; y en enero de 1555 se conoce una venta del arzobispo y del conocido mercader Alonso Pérez de Valenzuela, conjuntamente, a Juan López de Trujillo de una arria de animales y dos negros por 2.400 pesos $^{22}$. No se sabe si Loaysa y Pérez de Valenzuela eran socios en una compañía o no pero, en cualquier caso, es claro que el arzobispo disponía de animales de carga y esclavos con los que tomaba parte en el comercio de la Colonia.

Además de con Pérez de Valenzuela, Loaysa mantenía fluidas relaciones comerciales con otros mercaderes también conocidos, como con Luis de Baeza $^{23}$, Luis de la Peña y Juan Gómez de Anaya. Este último había otorgado poder al arzobispo para que tomase posesión por él de determinados indios que le habían concedido, poner mayordomo y cobrar tributos, así como saldar las cuentas de sus negocios, mientras que el arzobispo era Protector de Indios ${ }^{24}$. No es de extrañar, además, que Loaysa fuese prestamista; así, en 1559 fray Jerónimo seguía con sus operaciones económicas y prestó 4.000 pesos de plata marcada y ensayada, en 17 barras, al conocido mercader Francisco de Burgos quien, a cambio, escrituró un censo de 400 pesos al año sobre todas las casas y tiendas que tenía en Lima a favor del prelado ${ }^{25}$. En años posteriores el arzobispo siguió participando en otras operaciones, tanto con españoles -como las que mantuvo con el virrey Antonio de Mendoza y su hijo, D. Francisco-26 como con indios, que pasaron a engrosar su riqueza y a confirmar su capacidad mercantil y financiera ${ }^{27}$.

Ante esta actividad económica de fray Jerónimo de Loaysa caben dos reflexiones en la línea apuntada al comienzo. Una: que el prelado simultaneaba su función pastoral, que incluía a los indígenas, con su papel de encomendero, extrayendo altas cuotas de trabajo indígena para realizar fructíferos negocios personales. Y dos: que esta simultaneidad planteaba contradicciones en la evangelización de los indios. En su Instrucción ya citada de 1545, tras describir qué partes de la doctrina y cómo había que enseñarles a los indígenas, Loaysa ordenaba que, ya que los indios tenían "mucho que cumplir" económicamente con sus encomenderos -y sabía de lo que hablaba porque él era uno de ellos-, así como con las personas que habitualmente pasaban por sus 
pueblos -eran los años de las "guerras civiles"-, que no se les exigieran diezmos sobre el ganado y que de la producción agrícola solo se les pidiese el $5 \%$. Y, además, que había que explicarles que tenían que contribuir al sustento de los ministros de Dios y sus iglesias. Es decir, las exigencias económicas de alguien como Loaysa y otros eclesiásticos restaban sin duda a los indios tiempo y atención para dedicarle al aprendizaje de la doctrina.

Pero no era solo la alta jerarquía de la Iglesia la única que se beneficiaba del trabajo indígena. En 1551 el I Concilio de Lima -que en términos de doctrina siguió la Instrucción de 1545- dedicó varios de sus artículos a prácticas de los doctrineros, sacerdotes que se encargaban de la evangelización de los indios ${ }^{28}$. El primero se refirió a que los doctrineros no tuvieran con ellos "india ni mujer alguna", y que tampoco tuvieran con los indios negocios, ni comercio, ni tuvieran ganado, si no fueran algunas pocas cabezas. Por otro lado se castigaba con excomunión y 20 pesos cada vez que ocurriera el que los doctrineros cobrasen por administrar los sacramentos, añadiendo que había indios pobres que no podían pagar lo que exigían los curas. Por último, se prohibía que, como habían hecho algunos clérigos "por cobdicia", se incorporasen a expediciones de nuevos descubrimientos o de castigo a indios sin licencia de los prelados. Todo ello indica que seguramente había suficientes doctrineros que incurrían en estas prácticas, restando eficiencia a su tarea evangelizadora.

Años después, en 1567 se celebró el II Concilio Limense para aplicar a Indias las conclusiones del Concilio de Trento, y además de insistir en cuestiones doctrinales y prácticas pastorales tanto para españoles como para indígenas, en relación con estos últimos se aumentaban las advertencias acerca del comportamiento de los doctrineros en el terreno económico ${ }^{29}$. Así, se estableció que su salario sería fijado por los obispos y los curas no podrían exigir más a los indios; que los doctrineros no se quedaran con los bienes de difuntos ni obligaran a los enfermos a mandar misas en sus testamentos; que no organizaran negocios, ni comerciaran, ni tuvieran ganados con españoles o indios; que no cobrasen nada por administrar sacramentos ni por dar sepultura; y que no hicieran derramas entre los indios, estableciéndose sanciones por incumplimiento en todos los casos. Estas advertencias indican que estas prácticas se habían diversificado y continuaban a pesar de que ya se habían prohibido en el I Concilio. No obstante, en el III Concilio se reiteraron las mismas prohibiciones, pese a todo lo cual y hasta donde se conoce continuaban vigentes en el siglo XVII.

Todo lo anterior pone en evidencia que los intereses económicos estaban extendidos en el clero y en la misma institución eclesiástica, y que los efectos del ejercicio de dichos intereses afectaban seriamente a la vida de los indígenas y a sus posibilidades de atender al aprendizaje de la nueva religión.

\section{Los cabildos eclesiásticos}

Mientras que estos procesos tenían lugar, otros surgían y se reproducían en la Iglesia colonial. Uno de ellos tenía que ver con la evolución de los diezmos y sus consecuencias en la organización de la institución para cumplir con su labor evangelizadora. Como consecuencia del despegue económico tras los momentos iniciales de la Colonia, los diezmos comenzaron a crecer en las primeras diócesis que se erigieron: Cuzco, Lima, Quito, Charcas... ${ }^{30}$ Podría pensarse que con esta tendencia, además de con otros beneficios económicos que conseguía, la Iglesia no tendría problema para expandir su estructura pastoral. ${ }^{31}$ Sin embargo, la mayor disponibilidad de recursos no se traducía necesariamente en una mejor atención de las labores eclesiásticas.

En Lima, "desde que la tierra se pacificó", según el arzobispo Loaysa, los diezmos habían pasado de 11.000 pesos en 1548 a 18.000 en 1551. Por el contrario, en Cuzco, aunque solo coyunturalmente y porque "faltaba la paz", según el obispo Solano, los diezmos descendieron en aquellos mismos años y las protestas de Loaysa por este motivo disminuyeron ${ }^{32}$. Conviene señalar que durante décadas se mantuvo el debate de si los indígenas debían pagar diezmo o no y, en caso afirmativo, sobre qué productos. $\mathrm{La}$ casuística en este aspecto fue muy alta y, en todo caso, el diezmo de los indígenas, donde se pagó, se convirtió en otra carga económica que se sumó a las que la Iglesia les imponía ${ }^{33}$.

De todas formas, las diferencias entre los dos obispados referidos continuaron no solo por la disputa de límites entre ambas jurisdicciones, sino también por conflictos en torno al ejercicio de supervisión desde el arzobispado de Lima sobre Cuzco, lo que, entre otras cosas, afectaba a la recaudación y al manejo de las rentas en diferentes planos de la Iglesia, así como al nombramiento 
de párrocos y doctrineros en las diócesis. Estos conflictos tenían una repercusión directa en la vida interna de los cabildos catedrales, uno de los centros neurálgicos de la Iglesia colonial. Por un lado, pese a que sus rentas tendían a crecer, los obispos y cabildos eclesiásticos solicitaban al Consejo de Indias limitar el crecimiento del número de sus miembros -fijado en las respectivas cédulas de erección de las diócesis- sobre la base de que las rentas existentes no bastaban para sustentar a toda una plantilla completa.

Así, en 1551 solo estaban presentados en la catedral de Lima -es decir, con el visto bueno de la autoridad del Estado, el patrono de la Iglesia en Indias- el deán, el maestrescuela y un canónigo, y Loaysa pedía que se proveyera solo a seis nuevos miembros, entre dignidades y canónigos, porque con 4.500 pesos anuales no se podían sustentar más ${ }^{34}$. En Cuzco, la disminución coyuntural de unos diezmos que normalmente superaban los 30.000 pesos daba pie al obispo Juan Solano a afirmar que los recursos del obispado tampoco permitían sustentar a los nuevos canónigos llegados a la catedral ${ }^{35}$. Esta situación se mantuvo a lo largo de los años que tratamos y en 1567 el presidente de la Audiencia de Lima, Lope García de Castro afirmaba que:

... la renta de algunos obispados ha crecido, sobre todo en Cusco y Charcas, y aunque en las erecciones se manda que pueden proveer más prebendados, no están proveídos. Los prelados y cabildos se reparten entre sí los residuos [de los diezmos] que sobra (sic) y por ello no avisan a S. M. de los puestos vacos. Tanta renta tiene el arcedianazgo de Cuzco como el obispado de Quito ${ }^{36}$.

Los cabildos eclesiásticos se mostraban extremadamente celosos de su autonomía en el manejo de sus recursos y de los mecanismos de poder en sus respectivas ciudades. Un buen ejemplo lo proporciona lo sucedido en Cuzco inmediatamente después del I Concilio de Lima (1551), cuando el arzobispo decidió visitar la archidiócesis y comenzar por aquella ciudad. Loaysa sentía desde hacía tiempo un cierto celo respecto del obispado de Cuzco, además de las diferencias habidas con el obispo J. Solano, y ya había enviado anteriores visitas pastorales. Solo cuatro años antes, el clérigo Baltasar de Loaysa había visitado parte de la archidiócesis por delegación del arzobispo, pasando por Cuzco y La Plata, y llevando a cabo algunos negocios privados al mismo tiempo que sus tareas eclesiásticas ${ }^{37}$. Ahora, en 1552, Loaysa decidió enviar a Cuzco como visitador a otro clérigo de su confianza, Agustín de Sotomayor. Pero en Cuzco el obispo Solano, el cabildo eclesiástico y otros clérigos, violando las normas establecidas y en una muestra de desconfianza hacia el prelado limeño, no estaban dispuestos a dejarse visitar por el delegado del arzobispo. De manera que, por órdenes conjuntas de Solano y el cabildo, Sotomayor fue detenido, su documentación y acreditaciones le fueron sustraídas y fue hecho prisionero en la cárcel del obispado de Cuzco. ¿Qué tenía que ocultar el cabildo eclesiástico para no someterse a la jurisdicción del arzobispo? No es fácil contestar a esta pregunta, pero se puede tener una idea a partir del testimonio de un clérigo, Juan Ruiz, en la información que sobre los hechos llevó a cabo J. de Loaysa en 1553. J. Ruiz declaró que todos los vecinos de Cuzco se alegraban de que se enviase un visitador al obispado y que fuese a hacer justicia,

lo cual era menester porque los visitadores [internos, del propio obispado de Cuzco] que andan por el obispado que son tres o cuatro, dicen que hacen muchas sinrazones y agravios, llevando penas excesivas por cosas livianas, y que los vecinos decían que aquello no era ir a visitar, sino a robar... especialmente un Pedro Dalba, clérigo, que visita el término de Huamanga y otro clérigo Arévalo que visitó desde Cuzco hasta el Collao y los Andes [la ceja de selva] donde dicen que le dieron mucha cantidad de coca... ${ }^{38}$

Por tratarse de fecha tan temprana no existe documentación en el Archivo Arzobispal de Cuzco que confirme lo declarado por el testigo, pero se conocen comportamientos de visitadores en fechas anteriores y posteriores a 1552, como se verá más adelante, que hacen verosímil lo narrado por $\mathrm{J}$. Ruiz. La Iglesia no era una institución aislada del fenómeno colonial y con la economía en expansión, con la pérdida de poder de los encomenderos tras las Leyes Nuevas, con la presión sobre los indios intensificándose por parte de nuevos agentes coloniales como los corregidores, era normal que los vecinos y encomenderos de Cuzco protestaran 
por la competencia desleal que sufrían por parte de los visitadores eclesiásticos y de los doctrineros. La actuación de estos elementos en la vida de una diócesis remite a las relaciones internas de los cabildos eclesiásticos donde los puestos de visitadores pastorales eran muy apetecidos, recaían en personas de gran confianza de los obispos y no eran raras las disputas entre miembros de un cabildo por gozar de la influencia suficiente para lograr colocar como visitador a un allegado ${ }^{39}$. Finalmente Sotomayor fue liberado, pero se produjo un segundo intento de visita de nuevo fallido y solo a la tercera ocasión se pudo visitar el obispado de $\mathrm{Cuzco}^{40}$.

Pero el caso de Cuzco no era excepcional ni el más grave en términos de escándalo social. A fines de la década de 1550 en el obispado de Charcas también había problemas similares. Desde su creación, en 1552, la sede estaba vacante y los miembros existentes en el cabildo: deán, provisor, tesorero y algunos canónigos, debían estar controlando actividades no muy diferentes a las ya conocidas en Cuzco y transmitían la imagen de que el cabildo estaba "mal gobernado". Esto es lo que se percibía en el arzobispado y, en 1557, J. de Loaysa decidió intervenir en el ejercicio de sus funciones enviando a La Plata como visitador al arcediano de Lima, Bartolomé Martínez ${ }^{41}$.

Cuando el arcediano intentó iniciar la visita al cabildo de La Plata, sede de la diócesis, el deán, canónigos, prebendados y beneficiados se encerraron con provisiones y "armas ofensivas y defensivas", tales como ballestas y arcabuces, y negando la competencia del arzobispo para hacer dicha visita. La Audiencia, con sede en la misma ciudad, se pronunció apoyando la gestión del visitador, pero los miembros del cabildo eclesiástico no solo no obedecieron, sino que amenazaron con que, si era necesario, matarían al visitador B. Martínez y al Ldo. Altamirano, de la Real Audiencia y que, en cualquier caso, ellos morirían antes de consentir la visita aunque el rey, la Audiencia y el virrey lo obligasen $^{42}$.

El caso no era idéntico al de Cuzco, y aunque no es fácil adivinar toda la dimensión del conflicto se conoce una circunstancia en la visita que ayuda a entender en algo la situación. Se trata de que el arcediano y visitador B. Martínez había sido enviado a la visita con un salario que debería extraerse de la mitad de la parte de los diezmos correspondientes al obispo de La Plata, que por el momento no existía, debido a que la diócesis estaba en sede vacante. $\mathrm{Si}$ la dicha mitad no llegase a 3.000 castellanos -una suma importante- se le completarían de la otra mitad de los diezmos, además de los derechos derivados de las causas que ante él se tratasen y, por último, el cabildo eclesiástico de La Plata tenía, suplementariamente, la obligación de cubrir el sustento del visitador a razón de 5 pesos de oro al día. Al margen de cualquier otro problema de gobierno de la diócesis que estuviera pendiente, esta condición salarial del visitador era especialmente hiriente para el cabildo, porque afectaba a unos ingresos que sus miembros debían estar manejando con toda libertad y que ahora se verían mermados para pagar a su inspector. Finalmente, el asunto se resolvió de forma pacífica, aunque sin haberse completado la visita y sin castigo para los rebeldes.

Aparte de la dimensión escandalosa de estos casos, lo que revelan es que los intereses económicos de los eclesiásticos se cruzaban de forma determinante con el ejercicio de su labor pastoral limitándola seriamente en cuanto a la cobertura del clero y en cuanto a la relación con los feligreses, lo que estaba afectando también a la transmisión de la doctrina a los indígenas.

\section{El espacio de los doctrineros de indios}

Otros procesos que vivía la Iglesia tenían una relación aún más directa con la evangelización de los naturales. Uno de ellos derivaba de la obligación que también tenían los obispos de visitar en sus diócesis a párrocos y doctrineros tanto en el plano de cura de almas como en el de vita et moribus ${ }^{43}$. Frente a esta competencia de los obispos, reforzada por el Concilio de Trento, los doctrineros frailes o, en otros términos, las órdenes religiosas mostraron ya desde el siglo XVI una creciente resistencia a ser visitados en el segundo de los aspectos, argumentando que ello solo era competencia de los visitadores de su propia orden y no de los episcopales.

En términos generales, lo que se encerraba tras este conflicto era la posibilidad de controlar las relaciones no estrictamente religiosas de los doctrineros, frailes o clérigos, con la población indígena, lo que les permitía tener acceso a una parte de las importantes cantidades de recursos económicos de las comunidades. Las prohibiciones, reiteradas en los tres primeros Concilios de Lima, de que los doctrineros no reclamasen a los indios ni derechos por la administración de sacramentos ni por otros conceptos, así como que tampoco hicieran 
negocios de ningún tipo en sus doctrinas, no estaban siendo atendidas y, por el contrario, aquellos se habían convertido en agentes económicos muy dinámicos que absorbían grandes cantidades de excedentes de sus indios. Es difícil no recordar, como mínimo, la dinámica actividad económica del pastor de la diócesis, el arzobispo Jerónimo de Loaysa, quien debía ser un ejemplo para todos los sacerdotes del distrito.

El problema había adquirido rasgos más intensos y complejos con el desarrollo del sistema colonial, pero su origen se situaba en el comienzo de la conquista. Ciertamente las tres primeras décadas de la Iglesia en los Andes no habían sido fáciles para organizar la evangelización, aunque en ello tuvo mucha influencia la fuerza de los intereses por conseguir fáciles beneficios en corto espacio de tiempo. Uno de los primeros momentos del proceso de que se trata fue el de la relación entre los eclesiásticos -en su mayoría frailes- con los primeros encomenderos cuando pretendían convertirse en los doctrineros de estas encomiendas tempranas. Se trató de una fase variable según los territorios, que en algunos lugares de los Andes centrales quizá se prolongó hasta treinta años.

En los primeros años debió predominar una relación libre y casi contractual entre los encomenderos y los sacerdotes que debían hacerse cargo de la evangelización. Los religiosos circulaban por el territorio y ofrecían a los encomenderos sus servicios de predicar la doctrina a los indios. Cada encomendero era libre de arreglar, o no, con un cura su salario, pero si no se ponían de acuerdo en el estipendio, los indios se quedaban sin doctrinero ${ }^{44}$. Naturalmente, en los momentos iniciales de la Colonia había pocos curas y muchas encomiendas donde elegir. En última instancia y en el mejor de los casos, en una encomienda sin sacerdote algún seglar de confianza del encomendero podía encargarse de la explicación de la doctrina a los indios, lo que pudo generar una gran diversidad de líneas de explicación y riesgos de confusión, a lo que cabría añadir el probable desconocimiento de las lenguas nativas. De aquí la advertencia del Concilio de Lima, en 1551, de que los seglares no explicaran la doctrina, ello era una forma de forzar por otra parte la contratación de curas por los encomenderos y da idea de que en fecha tan avanzada existía la situación que se ha descrito $^{45}$. En cuanto al salario, parece lógico que, desde un comienzo, los encomenderos lo pagaran tomándolo del tributo que recibían de los indios, y esta fue la fórmula que finalmente se impuso después de las Leyes Nuevas.

A fines de la década de 1540 y comienzos de la de 1550 se aceleró el envío de religiosos al Perú. ${ }^{46}$ Tanto los dominicos, que eran los más numerosos, como los mercedarios, los franciscanos y los agustinos enviaron decenas de miembros de sus institutos a los Andes que hicieron crecer el número de sus casas, que hasta entonces eran muy pocas, en las ciudades y multiplicaron sus efectivos por el campo donde la situación era más tranquila que en los años de las "guerras civiles" 47 . Con esta expansión las órdenes religiosas fueron controlando la mayoría de las doctrinas de indios y también con ella pareció necesario dotar de algún instrumento al número creciente de doctrineros para ayudarles a realizar su labor. Por eso, en 1545 el obispo fray J. de Loaysa redactó la ya mencionada Instrucción para la doctrina de los naturales que se entregaba a los doctrineros, frailes o clérigos. ${ }^{48}$ En julio de dicho año el arzobispo escribía:

Desde que el Presidente [P. de la Gasca] entró en la tierra parece que la asentó. Los indios tratan [negocian] como españoles, vendiendo lo que tienen en los caminos y comprando como gente libre. Todo con mucha alegría. Así, reciben ahora más alegremente las cosas de la fe y se convierten y bautizan caciques, incluso los que han estado más duros. $\mathrm{Y}$ a estos les sigue la gente común y por ello no hay más dificultad en su doctrina. También se reparten los religiosos y los clérigos por los pueblos para doctrinarlos y sacramentarlos ${ }^{49}$.

Ante todo, Loaysa era agradecido con La Gasca, que le había concedido una encomienda, y comenzaba a contribuir a su imagen de "pacificador". Pero por otra parte, esta visión optimista de: pacificación $\rightarrow$ libertad de comercio $\rightarrow$ alegría de los indios $\rightarrow$ facilidad en la doctrina, que recuerda al pensamiento liberal, era como mínimo inverosímil y desde luego sesgada. Estaba seguramente guiada por la euforia de Loaysa de ver el crecimiento de sus diezmos, el beneficio de su segunda encomienda y de sus propios negocios pero, años más tarde, ya en la década de 1570 el propio Loaysa, además de muchos otros contemporáneos, confesaría al 
Consejo de Indias que las cosas no iban nada bien con la evangelización de los indios ${ }^{50}$.

Con el avance de la colonización, el clero, regular y secular, fue extendiéndose por la geografía andina en parroquias urbanas, en casas de órdenes religiosas y en doctrinas; estas últimas fueron atendidas durante las primeras décadas con mayoría de frailes sobre clérigos. A partir de esta circunstancia, el aumento del clero secular en la segunda mitad del siglo XVI, que no encontraba suficientes beneficios en qué ocuparse, vivió un momento crucial que tuvo lugar con ocasión del III Concilio Provincial de Lima (1582-83). Pierre Duviols calcula que solo en Lima había 100 clérigos sin ocupación en estos años frente a unos 300 cincuenta años más tarde ${ }^{51}$. Pese a no poder dar satisfacción a todos los clérigos sin empleo, la Iglesia iba a realizar un esfuerzo no solo por intentar ocuparlos, sino por intensificar la acción de sujeción de la población indígena al sistema colonial desde el punto de vista religioso que, hasta entonces, no había sido muy sólido.

En las sesiones del III Concilio se acordó reducir el número de indios por doctrina desde 400 "casados y demás de tasa" que había fijado el II Concilio, a "300 de tasa o 200" (sic) ${ }^{52}$. Llevando a cabo esta operación, el resultado inmediato sería el aumento del número de doctrinas por repartimiento $\mathrm{y}$, con ello, la posibilidad de que crecieran las ocupadas por clérigos. Sin embargo, parece que la letra de la ley no fue llevada a la práctica inmediatamente y, todavía en 1588, el obispo Toribio de Mogrovejo escribía al rey señalando la existencia de doctrinas con excesivo número de feligreses y apuntando a la conveniencia de que las autoridades civiles colaboraran en la puesta en práctica de lo establecido en el Concilio ${ }^{53}$. La Corona pareció hacerse eco de la petición de Mogrovejo y, así, en las Instrucciones dadas al virrey Luis de Velasco en junio de 1595 se le advertía sobre el aumento del número de monasterios, doctrinas y haciendas en poder de los religiosos y se le reiteraba el encargo que ya se había hecho, en 1593, al virrey Marqués de Cañete de que enviase relación de todo ello al Consejo ${ }^{54}$. Poco más tarde, en diciembre del mismo 1595, se le ordenaba reunirse con el arzobispo y los prelados de las órdenes para poner arreglo a los grandes inconvenientes derivados de que los religiosos continuasen al frente de la mayor parte de las doctrinas ${ }^{55}$.

Finalmente este interés pareció surtir efecto, y aunque probablemente los límites de feligreses por doctrina establecidos en el III Concilio nunca se cumplieron fielmente o solo en la medida en que descendía la población indígena, a lo largo de la década de 1590 el aumento del número de doctrinas destinadas a clérigos en el arzobispado fue importante, con lo que al menos se consiguió encontrar sitio para algunos de los clérigos sin beneficio. Así, en 1593 existían en la archidiócesis 219 doctrinas, de las que 121 estaban regentadas por religiosos y 98 por clérigos, pero seis años más tarde, en 1599, los frailes seguían estancados en 122 doctrinas pero los clérigos disponían ya de 118 , y es de suponer que esta tendencia continuase en años siguientes a juzgar por el hecho de la creación de nuevas doctrinas ${ }^{56}$.

Este proceso despertó rivalidad entre ambos sectores del clero y, en relación con el aspecto de la intervención de los sacerdotes en economía en las doctrinas, desde fines del XVI y de forma más abundante a comienzos del XVII, se producían acusaciones cruzadas entre el clero regular y secular sobre la actividad de los doctrineros pero también sobre la tolerancia de los visitadores pastorales respecto de sus prácticas. Así, fray Pedro Gutiérrez Flores, o.f.m., informaba al rey en 1606 de que, entre otras prácticas económicas, algunos visitadores del arzobispado de Lima llegaban a conseguir en dos años de su labor entre 20.000 y 30.000 ducados por esta vía ${ }^{57}$. De hecho, desde el III Concilio ya existían advertencias sobre la forma en que debían llevarse a cabo estas visitas, recomendándose moderación en el comportamiento de los visitadores, lo que es señal de que no la había en suficiente medida ${ }^{58}$. Además, a los obispos y miembros del cabildo eclesiástico iba destinada la "cuarta funeral", que era un porcentaje de los ingresos habidos por los curas por los derechos eclesiásticos en los funerales, que los doctrineros tenían prohibido cobrar, pese a ello era recolectado en las visitas a párrocos y doctrineros, lo que era una flagrante contradicción. Aunque pudieran existir dudas por no aparecer recogido este ingreso en la documentación contable religiosa, las denuncias de los frailes y hasta de la Audiencia en este sentido son inequívocas ${ }^{59}$.

Pero los frailes, por su parte, no estaban exentos de estos problemas. En su caso, el dinero ofrecido a los delegados de sus superiores, en las visitas que estos realizaban a las doctrinas regidas por miembros de sus órdenes, tomaba el nombre de "besamanos" y adquiría niveles de hasta 500 y 1.000 pesos por doctrina. Algún testigo de la información sobre las 
doctrinas de los frailes realizada por el arzobispo de Lima, en 1614, afirmaba que los superiores de los religiosos salían muy ricos de las visitas, al tiempo que narraba la confesión que un fraile doctrinero le había hecho:

...todo el año andamos afanando y juntando plata para tres cosas, una el convento, otra nuestro padre provincial y otra para nobis; y la parte de nuestro provincial la tenemos apartada lo primero y así todo se absuelve con agua bendita, porque aunque hagamos las doctrinas como San Pablo, si no hay pecunia no quedamos en ellas, y así procuramos siempre tener plata prevenida para esto... ${ }^{60}$

Este tipo de testimonios no hacía más que confirmar las sospechas y denuncias que surgían de los problemas referidos más arriba en Cuzco y Charcas. No es fácil calcular el nivel de excedente económico que, bajo diversas formas -indios como fuerza de trabajo, dinero, productos, etc.-, podía ser apropiado por un doctrinero de "tipo medio" en términos económicos y demográficos, pero existen numerosos testimonios que revelan el alto interés de muchos curas de indios por obtener notorios beneficios materiales de sus feligreses. Por poner solo un ejemplo, citemos las palabras de Dr. Luis López, Provincial de San Agustín en Lima, sobre el estado de las doctrinas, escritas en 1572. Tras lamentar el bajo nivel de instrucción y catequización de los indios, el agustino escribía:

... pero vemos claramente que el (eclesiástico) más desgarrado y de peor ejemplo, por contentar a dos o tres del Cabildo o servir al prelado, alcanza la mejor doctrina y de mejor salario y el bueno anda abatido, y por esto a ninguno se le da nada, sino todos se encomiendan a la buena ventura y el que más puede granjear y rescatar [negociar y comerciar] y volverse más presto a España rico, ese es el más hábil y así todo lo paga la doctrina de los pobres naturales ${ }^{61}$.

Para comienzos del siglo XVII existen al menos datos aproximados que apuntan a que las cantidades, traducidas en dinero, del excedente obtenido por un doctrinero medio en los Andes centrales, bien fuera religioso o clérigo, eran bastante altas y podían ascender a más de 5.000 pesos al año en doctrinas ricas $^{62}$. Reforzando la línea de este cálculo, el virrey Marqués de Montesclaros afirmaba en los inicios del siglo XVII que "la más ruin doctrina vale más el día de hoy que ningún repartimiento"63. Los métodos utilizados por los doctrineros para extraer de cuotas de excedente económico indígena eran de lo más variado, yendo desde administrar y apropiarse de los bienes de cofradías hasta tener tierras y ganado en propiedad que eran cultivadas y cuidado con fuerza de trabajo indígena, fabricar tejidos, muebles, pólvora u otras mercancías, tener negocios de comercio con los que trasladar al mercado estas producciones, pero también exigir obvenciones por la administración de sacramentos -lo que estaba prohibido- y limosnas, a veces forzosas, en productos o en dinero. Es importante destacar que para ampliar la cuota de excedente muchos doctrineros no dudaban en tolerar o incluso estimular prácticas religiosas prehispánicas a cambio de las cuales demandaban cantidades de dinero u ofrendas en productos. Es decir, que en lugar de combatir dichas prácticas, como supuestamente deberían hacer, muchos curas las admitían en su propio beneficio, lo que significaba una contradicción en los propios términos de la evangelización ${ }^{64}$.

A partir de lo anterior se puede tener una idea de la constante presión económica que ejercía la Iglesia sobre el mundo de las comunidades indígenas en el plano de las doctrinas y, sobre todo, en repartimientos donde se crearon más de una; huelga decir que las expectativas de cada doctrinero, ya se incorporase a una doctrina antigua o a una de reciente creación, debían ser las de reproducir las pautas de comportamiento de los que ya existían y conseguir, como mínimo, el mismo nivel de ganancias que el obtenido por sus colegas y predecesores.

\section{Conclusiones: el discurso}

Después de un siglo puede decirse que se había consolidado un determinado orden en las relaciones sociales y económicas coloniales que cabría calificar de estructural. En dicho orden, la Iglesia se había situado mayoritariamente, institucional e individualmente, en el espacio dominante, aunque con matices y diversidad de grados. De esta forma y por distintas vías extraía importantes cuotas de excedente del mundo indígena que, convertido en valor, añadía al que obtenía también del ámbito de la población peninsular, criolla y esclava. Por lo que 
respecta a los indígenas, esta posición de la Iglesia la condujo a elaborar, en el marco de la religión católica, un discurso justificativo del citado orden de relaciones sociales y económicas, que puede decirse que constituyó la base de lo que cabe denominar como la teología de la dominación ${ }^{65}$. De los varios ejemplos que se pueden citar sobre este hecho se cita aquí el tomado de un sermonario para indios elaborado en torno a 1600, que terminó publicándose en Lima en 1649, y cuyo autor fue Fernando de Avendaño, precisamente un doctrinero - con una relación económica con los indios de su doctrina en la línea de lo expuesto- y posteriormente canónigo de la catedral de la capital del virreinato ${ }^{66}$. Lo explícito del texto resume claramente el sentido que se ha querido transmitir en este trabajo.

... Me preguntareis, ¿por qué causa ordeno Dios que uviera tantos hombres pobres en el mundo? Mirad hijos, assi lo quiso Dios y un sabio filosofo llamado Aristoteles dixo que hay hombres que Dios crio para servir a otros, como son los negros. Porque si todos fueran ricos, si todos tuvieran mucho oro y plata, ninguno quisiera servir a otro, ninguno aprendiera los oficios de cansancio y trabajo; ningun hombre quisiera ser albañir (sic), ni cargar adobes para hazer las paredes, ninguno quisiera cabar, arar ni sembrar las chacras, ninguno quisiera ser pescador, ni ser marinero, ni andar con los navios que no duermen de noche, ninguno quisiera guardar las ovejas en las punas entre la niebe. Porque todos estos oficios de cansancio y trabajo los hacen los hombres pobres. Veis aquí hijos la razon por que la providencia de Dios quiso y ordeno que uviera hombres pobres en el mundo: porque las republicas y ciudades estuvieran bien concertadas y pudieran unos hombres servir a otros.

Dime, ¿podras tu con razon quexarte a Dios y dezirle: "Gran Señor ¿por qué me hiziste Indio pobre para yr a la mita y al obraje y a guardar las ovejas en la puna?". No por cierto. ¿Quiereslo ver? Pues oyeme atentamente. Quando el ollero esta haziendo jarros y ollas, unos para mesas de señores y otros para la cozina, ¿podra la olla quejarse al ollero (si tuviera entendimiento): para que me hiziste olla para cozina y no me hiziste jarro para mesa de señores? No por cierto. ¿Por qué? Yo te lo dire: porque esso pende de la voluntad del ollero; este por su voluntad haze del barro ollas a quien quiere y del mismo barro haze jarros a quien quiere.

De la misma manera, hijo, Dios todo poderoso es como el ollero y los hombres somos como el barro, y Dios por su voluntad haze unos hombres para Reyes y nos manden, y otros para que sean vasallos y les paguen tributo. Assi tambien cria unos para servir y otros para mandar, unos pobres y otros ricos; y assi como la olla no se puede quexar del ollero..., el hombre no se puede quexar con razon de Dios porque lo hizo Indio y no Español, y porque lo hizo pobre y no rico; porque el barro no tiene derecho para ser jarro y no olla, ni el hombre tiene derecho alguno para ser rico y no pobre. Esso, hijos, pende de la voluntad de Dios. Y por esso debes dar muchas gracias a Dios, porque si uvierais nacido rico, fueras sobervio, y tuvieras muchas mugeres; y quisieras quitarle al pobre su chacra y te fueras al infierno. Y siendo pobre te libra Dios de todos essos pecados. ¿Veis todo el oro y plata que dio Dios nuestro Señor a los ricos? Pues no se la dio de valde, sino para que socorran a los pobres y los ayuden con sus limosnas... si no, ellos se yran a los infiernos y los pobres yran al cielo donde no les faltara nada; los pobres estaran muy contentos en el cielo y los ricos muy tristes llorando en el infierno; los pobres estaran en el cielo en compañía de Dios y los ricos estaran en el infierno en compañía de los Demonios; los pobres tendran mucha gloria en el cielo y los ricos padeceran muchos tormentos en el infierno. No te pese hijo de ser pobre en esta vida, que se ha de acabar muy presto y iras a ser rico al cielo para siempre mientras Dios fuere Dios ${ }^{67}$. 


\section{Referencias Citadas}

Acosta, A.

2014 Prácticas coloniales de la Iglesia en el Perú. Siglos XVI-XVII. Sevilla: Aconcagua.

2001 Dogma católico para indios: la versión de la Iglesia católica del Perú en el siglo XVII. Histórica, XXV, 2. Lima: Pontificia Universidad Católica del Perú: 11-47.

1987 Estudio biográfico sobre Francisco de Ávila. En G. Taylor y A. Acosta, Ritos y tradiciones de Huarochirí del siglo XVII. Lima: IEP: 551-616.

1982 Religiosos, doctrinas y excedente económico indígena en el Perú a comienzos del siglo XVII. Histórica. Lima: Pontificia Universidad Católica del Perú, 6, 50: 1-34.

Aldea, Q., Marín, T. y Vives, J. (Dirs).

1985 Loaysa, García de, o.p. Diccionario de Historia Eclesiástica de España. Madrid: CSIC: tomo II.

Armas Medina, F. de.

1953 Cristianización del Perú (1532-1600). Sevilla, Escuela de Estudios Hispanoamericanos.

Avendaño, F.

1649 F. de Avendaño, Sermones de los misterios de nuestra santa fe católica, en lengua castellana, y la general del Inca: impúgnanse los errores particulares que los indios han tenido. Lima: Jorge López de Herrera.

Bauer, A.

1986 La Iglesia en la economía de América Latina, siglos XVIXIX. México: INAH.

Borges Morán, P.

1977 El envío de misioneros a América durante la época española. Salamanca: Universidad Pontificia.

Carmona Vergara, V.

1989 Conflictos sociales y políticos en torno a los diezmos en el arzobispado de Lima.1560-1600. II Encuentro de Jóvenes Historiadores. Lima: Pontificia Universidad Católica del Perú.

Cieza de León, P. de

1984-85 Obras Completas II. Las Guerras Civiles Peruanas, La Guerra de Quito (Carmelo Sáenz de Santa María, ed.). Madrid: CSIC.

Clemence, S. R. (Coord.).

1932 The Harkness Collection in the Library of Congress. Calendar of Spanish Manuscripts concerning Peru. 15311651. Washington: United States Government Print Office.

Cook, N. D.

1981 Demographic Collapse: Indian Peru, 1520-1620. Cambridge: Cambridge University Press.

Dammert Bellido, J.

1996 El clero diocesano en el Perú del siglo XVI. Lima: Instituto Bartolomé de las Casas, Rímac.

Dussel, E.

1973 Dominación-liberación. Un discurso teológico distinto. Caminos de liberación latinoamericana II: teología de la liberación y ética. Buenos Aires, Latinoamérica Libros: 195-221.

Duviols, P.

1986 Cultura andina y represión: procesos y visitas de idolatrías y hechicerías. Cajatambo siglo XVII. Cusco: Centro de Estudios Rurales Andinos Bartolomé de las Casas.
Díaz Cuenca, J.

2009 Iglesia y nobleza en la Sevilla bajomedieval. Anuario de Estudios Medievales (CSIC) 39/2: 877-931.

2000 La Iglesia conquense en la Edad Media. Estructura institucional y relaciones de poder. Anuario de Estudios Medievales, (CSIC), 30/1: 277-318.

Egaña, A. de S.J,

1966 Historia de la Iglesia en la América Española. Madrid: Editorial Católica.

Escudero Buendía, F.J.

2003 Antonio de Mendoza, Comendador de la villa de Socuéllamos y primer Virrey de la Nueva España. Socuéllamos: Perea Ediciones.

Guibovich Pérez, P.

1993 La carrera de un visitador de idolatrías en el siglo XVII: Fernando de Avendaño (1580?-1655). En Gabriela Ramos y Henrique Urbano (Compils), Catolicismo y extirpación de idolatrías, siglos XVI- XVIII. Cusco, Centro de Estudios Regionales Andinos "Bartolomé de Las Casas": 169-240.

Levillier, R. (Ed.).

1921-26 Gobernantes del Perú. Cartas y papeles. (siglo XVI): documentos del Archivo de Indias. XV vols. Madrid, s/n.

Lissón Chaves, E. y Ballesteros Gaibrois, M. (Eds.)

1943-46 La Iglesia de España en el Perú. Colección de documentos para la Historia de la Iglesia en el Perú... Sevilla: Editorial Católica Española.

Numhauser, $\mathrm{P}$.

2005 Mujeres indias y señores de la coca. Potosí y Cuzco en el siglo XVI. Madrid: Cátedra.

Pérez de Tudela, J. (Ed.)

1964 Documentos relativos a D. Pedro de la Gasca y a Gonzalo Pizarro. Madrid: Real Academia de la Historia.

Pérez Fernández, I.

1988 Bartolomé de las Casas en el Perú: el espíritu lascasiano en la primera evangelización del imperio incaico (1531-1573). Cusco: Centro de Estudios Rurales Andinos Bartolomé de las Casas.

Pike, R.

1966 Enterprise and Adventure. The Genoese in Seville and the Opening of the New World. Ithaca-New York: Cornell University Press.

Porras Barrenechea, R.

1948 El cronista indio Felipe Huaman Poma de Ayala. Lima: Lumen.

Puente Brunke, J. de la

1992 Encomienda y encomenderos en el Perú, Sevilla, Diputación Provincial.

Rodríguez Valencia, V.

1957 Santo Toribio de Mogrovejo. Organizador y Apóstol de Suramérica. Madrid: CSIC, 2 vols.

Rojas Rabiela, T. y Murra, J.V. (coords.)

Las sociedades originarias, en Historia General de América Latina, I. Madrid-Paris: UNESCO-Trotta.

Stern, $\mathrm{S}$.

1982 Peru's Indian Peoples and the Challenge of Spanish Conquest. Huamanga to 1640. Madison: University of Wisconsin.

Vargas Ugarte, R.

1959 Historia de la Iglesia en el Perú. Burgos: Aldecoa.

1951 Concilios Limenses (1551-1772). Lima, s/n. 


\section{Apéndice}

[En julio de 2014 Henrique Urbano escribió unas palabras, a solicitud del autor, como Prólogo al libro que Antonio Acosta estaba publicando con el título Prácticas coloniales de la Iglesia en el Perú, siglos XVI-XVII (Sevilla, Ed. Aconcagua, 2014). A los editores de este volumen y al propio autor del libro y del siguiente artículo les ha parecido oportuno reproducir dicho texto por varias razones: por ser uno de los últimos escritos de Henrique Urbano, por cómo recordaba en él sus primeros años en Cusco, por lo que refleja de su carácter y sentido del humor y, finalmente, como introducción al propio trabajo de Antonio Acosta $]^{68}$.

¡Qué grata sorpresa!... Es una gran alegría poder dedicar a las investigaciones de Antonio Acosta unos breves párrafos y sellar con ellos una vieja amistad. Viene de los años 70 u 80 del siglo pasado. ¿Quién lo hubiera adivinado? ¡Misterio muy misterioso! Por caminos tan extrañamente diversos, por paisajes culturales tan contrastados, hemos llegado a un punto imaginario que, según dicen los griegos, el inexorable destino reserva para sus héroes. Sin ir tan lejos y a tan eruditas fuentes, creo que solo la búsqueda de la sexta vía de conocimiento de Dios podrá dar razón de ello.

Existía por ese entonces en el paisaje cultural cuzqueño un olor a novedad. El dictador Velasco rompía con el pasado. Y la historiografía inconscientemente sentía dolores de parto. Quedaban, es cierto, resabios de caciques, gamonales, patrones, jefes de bandos, terratenientes empobrecidos, intelectuales anclados en la más férrea ignorancia, herederos de principios discursivos que desafiaban al más mínimo intento de conocimiento racional. $\mathrm{Y}$ cosa curiosa y extraña, se difundía un generalizado palabreado supuestamente marxista, pero que, de hecho, era fruto de frívolas recetas dogmáticas, que me recordaban esas sesiones dominicales de mi infancia en que se repetían hasta la saciedad definiciones tan sublimes e incomprensibles como las de Dios Uno y Trino, del Catecismo romano de Pío X.

Discurrían, pues, los años y llegados los idos de mayo de 1974, aún me quedaba mucho -para no decir todo- por conocer en ese mundo opaco y recio que era el Sur andino. Acosta aún no había llegado, tampoco se escuchaba el eco de su Veni
Creator Spiritus en la piedra de doce ángulos, ni en los casi 400 ceques con que el antropólogo R. T. Zuidema contaminó el Templo del Sol y alrededores. Sin embargo, fue el año en que yo firmé el Acta de Fundación del Centro de Estudios Rurales Andinos "Bartolomé de Las Casas". Los cuatro fundadores constituían una especie de Quarteto cátaro: Guido Delran, de Albi; Juan Hugues, de Toulouse; Juan B. Lassègue, vasco pirenaico; y yo, luso, llegado desde lo más occidental de la Península. Y luego Bernardo Fulcrand, de Béziers, quien aportó al grupo adámico un conocimiento especializado en vacas, alpacas, ovejas, quesos y chorizos.

Si yo recuerdo todos esos sencillos hechos es porque, años más tarde, ahí ocurrirá la epifanía de Antonio Acosta. Cuando él llegó, el Centro Las Casas era una mansión acogedora e innovadora, donde se multiplicaban los debates, los intercambios académicos y las investigaciones científicas. Yo me encargaba del Colegio Universitario con cursos de posgrado en Estudios Andinos y, en 1983, fundaba la Revista Andina y en seguida, en 1986, los Cuadernos para la Historia de la Evangelización en América latina. En todas esas actividades, Antonio Acosta desempeñó un papel relevante. Su apoyo en esos momentos fue decisivo para el Centro Las Casas y para mí. Nunca me olvidaré de su sencilla y abierta amistad, de su alegría y comprensión. A todo ello, añadía yo, mi propio interés por sus investigaciones, que contribuyeron a la renovación de un campo importante de la historiografía peruana, la de la historia de la Iglesia. Lo recuerda Antonio Acosta en su "Introducción". Por eso no insistiré sobre ello. Su innovador punto de vista, a lo que globalmente él llama "prácticas coloniales de la Iglesia", subraya una dimensión del quehacer eclesiástico sin duda importante y hasta ese entonces poco o nada desarrollado. Ese afán por acumular 'alimentos terrestres' por una institución que se llenaba la boca de 'alimentos celestes' da cabida a una práctica catequística que Antonio Acosta describe en base a una novedosa documentación archivística. Lo sabemos hoy mejor que nunca, los 'doctrineros' -curas, religiosos y hasta obispos- se dejaban llevar por sus pasiones y, en no pocos casos, olvidaban el lejano hanan pacha por extensos topos de tierra del kay pacha. Más codiciada era la mano de obra, y muchos clérigos y religiosos la retenían 
para sus servicios y chácaras. ¿Y la minería? Es una veta poco explorada aún. Hasta Cristóbal Albornoz y su sobrino poseían minas de oro en Vilcabamba, en tiempos del Inca rebelde. De ahí -iquién sabe!- le vino la idea del taqui onqoy... ¿"Prácticas coloniales"? Pues sí.

Otro tema que Antonio Acosta supo renovar es el del proyecto catequético de Francisco de Ávila y de los jesuitas, asumido luego por el obispo Lobo Guerrero. Se conoce también por "extirpación de idolatrías", en gran parte debido a la obra de Arriaga La extirpación de la idolatría en el Pirú (1621), que se alzaba como un auténtico manual para todos aquellos que se entregaban a la difusión de la doctrina christiana en el Arzobispado de Lima. La versión y nueva traducción de los textos de Huarochirí en que participó Antonio Acosta con un estudio biográfico sobre Ávila rompió con una tradición de corte indigenista y folclórico. Hombre culto y polifacético, Ávila no encaja en una visión simplista de la historia de la evangelización del Perú. Sin embargo, si Antonio Acosta no hubiera roto el hielo, proporcionándonos datos documentales novedosos, quizá no hubiéramos llegado adonde hoy día llegamos, es decir a nuevos horizontes históricos, a perspectivas hermenéuticas muy distintas de las que nos legaron los años de la segunda mitad del siglo XX. Por todo ello pues, me da mucha alegría releer estas páginas y saborear aún en medio de ellas nuestras noches fraternas y eruditas en los bares cuzqueños, en que, ya avanzada la noche, Antonio Acosta, retomaba casi en sordina, las primeras notas del venerable canto Veni Creator Spiritus... Era su Oda a la Alegría, corona de una sinfonía que ojalá tarde aún muchos años en llegar a sus últimos acordes.

\author{
Henrique Urbano \\ Universidad de San Martín de Porres \\ Lima-Perú, julio de 2014.
}

\section{Notas}

1 En Castilla y en el resto de Europa la Iglesia ya tenía una tradición de relación con el poder económico. Ver, por ejemplo Cuenca (2000 y 2009). Sobre la financiación de Colón, ver Pike (1966: 3). Un ejemplo en esta línea fue Stern (1982).

Ver Rojas Rabiela y Murra (2003).

Ver por ejemplo, Arnold Bauer (1986).

Dammert Bellido (1996).

Puente Brunke (1992: 437).

Ver la entrada "Loaysa" en Aldea, Marín y Vives 1985, t. II: $426 \mathrm{ss}$.).

Cook (1981)

10 Archivo General de la Nación del Perú (en adelante AGNP), Protocolos, 153. Los diezmos del Cuzco continuarían subiendo, manteniendo las diferencias con Lima, entre otras razones, gracias a la importancia de la coca en la expansiva economía mercantil colonial. Ver: Numhauser (2005).

11 Su Majestad (S. M.) a fray Juan de Solano, Guadalajara, 21 de septiembre de 1546, en Lissón Chaves y Ballesteros Gaibrois (1943-46, vol. 1, no 4: 150-151). (En Archivo General de Indias, en adelante AGI, Lima 566, lib. 5, f. 237).

12 Estos indios habían sido originalmente del difunto obispo fray Vicente de Valverde y, a su muerte, habían sido concedidos por el propio Vaca de Castro al contador de la Real Hacienda Juan de Cáceres, quien lógicamente protestó porque ahora fueran otorgados al obispo. Clemence (1932: junio de 1542 y octubre de 1543). Jerónimo de Loaysa, actuando en nombre de la Iglesia, entabló también un pleito contra $D^{\text {a }}$ María Valverde -hermana de fray Vicente Valverde-y su marido por unas casas, estancia y vestimentas brocadas de fray Vicente. Tras una sentencia favorable al obispo y una apelación del matrimonio a la Audiencia, Loaysa rechazó la apelación y confirmó la sentencia. Ver Clemence (1932: mayo-junio de 1544, 169).

13 Pérez Fernández (1988).

14 Cieza de León (1984-85: 313-314). J. de Loaysa llegó a admitir que pudo ser cierto, aunque sin su consentimiento, y el sacerdote Baltasar de Loaysa (no familiar del obispo) aseguró que había sucedido.

15 Pérez de Tudela (1964, t. II: 41 y 152-153).

16 Lissón Chaves y Ballesteros Gaibrois (1943, vol. 1, n 4: 135-145).

17 Ver los informes de Luis Lara, Juan Sánchez y Alonso de Montemayor sobre el asunto en AGI, Lima 118.

18 Loaysa fue nombrado arzobispo en 1546. Ver Egaña (1966: 45).

19 Toda la información referente a la obtención de la segunda encomienda por parte de J. de Loaysa procede del pleito entre D. Pedro Portocarrero y Da. María Escobar su mujer, con el arzobispo, en AGI, Justicia 397.

20 AGNP, Protocolos 9. El mismo arzobispo afirmaba la seguridad de la renta inmobiliaria. Ver fray J. de Loaysa a S.M Lima, 24 de julio de 1549. Lissón Chaves y Ballesteros Gaibrois (1943. Vol. 1: 205).

21 AGNP, Protocolos 160. En este comercio participaba Gil Ramírez Dávalos, mayordomo del virrey Antonio de Mendoza.

22 AGNP, Protocolos 64

23 AGNP, Protocolos 64

24 AGNP, Protocolos 160

25 AGNP, Real Audiencia, legajo 5, cuaderno 30 (julio 1559) y Protocolos 123.

26 Escudero Buendía (2003). En cuanto a poderes, en 1556 F. de Mendoza le facultó para elegir por él repartimientos 
y ocuparse de la administración de sus bienes. AGNP, Protocolos 123 y 125. Protocolos 124. Por otra parte, en 1569 Loaysa se benefició del producto de la venta de una viña perteneciente al cacique D. García Nazca, quien se la entregó en su testamento. Ver AGNP, Derecho Indígena, 31, c. 616. Vargas Ugarte (1951)

Vargas Ugarte (1951).

Egaña (1966).

Sobre quién tenía que pagar diezmo y sobre qué en la Colonia temprana, Carmona (1989).

J. de Loaysa a S. M., Lima, 9 de marzo de 1551, AGI, Lima 300 y J. Solano a S. M., Cusco, 20 de diciembre de 1549. AGI, Lima, 305. Pese a la diferencia de fechas de las cartas, es interesante la diferente valoración sobre la situación social de ambos prelados, y el reconocimiento implícito de Loaysa a La Gasca por su tarea "pacificadora". Ver nota 32.

Del total del diezmo en 1548, que había sido de 18.000 pesos, al cabildo correspondía el $25 \%$, es decir, 4.500 pesos, que parecían insuficientes para sustentar a más de 9 personas.

Los diezmos de Cuzco supusieron 34.000 pesos en 1548. V. J. de Loaysa a S. M., 3 de febrero de 1549. AGI, Patronato 192, n1, R. 55.

Lope García de Castro a S. M. Lima, 20 de diciembre de 1567, en Levillier (1921-1926, III: 270). Los residuos a que se refiere la cita eran la parte de los diezmos correspondiente a las plazas del cabildo no cubiertas.

AGNP, Protocolos 64.

Información sobre la prisión del Lcdo. Sotomayor... Lima, 1553, en Lissón Chaves y Ballesteros Gaibrois (1943-46, vol. 2, no 9: 541).

Sobre control de abusos de visitadores, Vargas Ugarte (1951, t. III, $4^{a}$ sess. Const. 1 y 4).

1 Testimonios presentados por F. J. de Loaysa sobre lo sucedido en la visita... Lima, 30 de marzo de 1559. Lissón Chaves y Ballesteros Gaibrois (1943-46, vol. 2, $\mathrm{n}^{\circ}$ 5: 98).

Relato de La Plata, 5 de enero de 1558, ibidem.

Sin una razón de peso en principio, la Iglesia decidió que la población indígena urbana fuera atendida en parroquias, a veces específicamente para indios, como en barrios de México o Cuzco, mientras que los indios rurales fuesen atendidos en doctrinas por doctrineros. Estos eran de hecho sacerdotes con las mismas funciones que los párrocos urbanos y que, de hecho, habían servido a veces, o servirían, ellos mismos parroquias. Ello equivalía a considerar a la población indígena rural

como minorenne, a pesar de que individuos o familias de estas poblaciones pudieran emigrar a una ciudad y pasar a ser considerados al día siguiente fieles en su más plena dimensión, lo que suponía una contradicción desde el punto de vista canónico.

44 Vargas Ugarte (1951, t. I): Actas del I Concilio de Lima, Sección naturales, Constitución 28, p. 23.

$45 \quad$ Ibidem, Const. 34, p. 27.

46 Borges Morán (1977).

47 Armas Medina (1953, cap. V y ss.) y Borges Morán (1977).

$48 \quad$ Ver nota 17.

49 F.J. de Loaysa a S. M. Lima, 24 de julio de 1549. Lissón Chaves y Ballesteros Gaibrois (1943-46, vol. 2, n 4, 171).

50 F. J. de Loaysa a S. M. Lima, 25 de mayo de 1572, AGI, Lima 300.

51 Ver Duviols (1986), Egaña (1966: 295).

52 Ver Vargas Ugarte (1951, t. III, $3^{\text {a }}$ acción, cap. 11: 93-94).

53 Lissón Chaves y Ballesteros Gaibrois (1943-46, vol. 3, $\mathrm{n}^{\circ}$ 15: 484).

$54 \quad$ Ibid. IV, $\mathrm{n}^{\circ}$ 18: 161.

55 Ibid.: 166.

56 Ver Rodríguez Valencia (1957, t. II: 104-105). Las listas de doctrinas y curas publicadas por Lissón Chaves y Ballesteros Gaibrois para los años 1599, 1602 y 1604 presentan un número menor en ambos apartados, quizá porque algunas de las primeras estuvieran sin cubrir en los citados años. De hecho, así sucede por ejemplo en 1604 en relación a 1602 con Aquia-Collana de Lampas y el cura Francisco Caro. Cfr. Lissón Chaves y Ballesteros Gaibrois (1943-46, vol. 4, nos. 19, 20 y 21).

57 Fr. P. Gutiérrez Flores, Provincial de S. Francisco en Perú a S. M. Lima 18 de mayo de 1606. AGI, Lima 323.

58 Vargas Ugarte (1951, t. I, Conc. III, sess. 4 ${ }^{\text {a }}$, caps. 1-4).

59 Real Audiencia de Lima a S. M. Lima, 8 de marzo de 1627. AGI, Lima 308.

60 Información promovida por Bartolomé Lobo Guerrero, arzobispo de Lima, "en razón de los excesos que los religiosos de las órdenes hacen en las doctrinas que están a su cargo", 1614. AGI, Lima 301.

61 Lissón Chaves y Ballesteros Gaibrois (1943-46, vol. 2, $\mathrm{n}^{\circ}$ 9: 590).

62 Acosta 1982, 1: 1-34.

63 Porras Barrenechea $(1948,47)$.

64 Acosta (1987: 577 ss.).

65 El concepto ya ha sido utilizado. Ver por ejemplo Dussel (1973).

66 Guibovich Pérez (1993), Acosta (2001, 2: 11-47).

67 Avendaño (1649, Parte Primera, Sermón V: f. 71).

68 Palabras de presentación de un texto de Henrique Urbano. Consensuadas entre los editores y Antonio Acosta. 
